\title{
The Effect of the Installation Angle of the Sky Quality Meter on the Night Sky Brightness and the Beginning of the Fajr Prayer Time
}

\author{
Abu Yazid Raisal*, Muhammad Hidayat, Leo Hermawan and Arwin Juli Rakhmadi \\ Observatorium Ilmu Falak, Universitas Muhammadiyah Sumatera Utara \\ J1. Denai No.217, Kec. Medan Denai, Medan, Sumatera Utara, Indonesia \\ *Email: abuyazidraisal@gmail.com
}

\begin{tabular}{|c|c|}
\hline Article Info & ABSTRACT \\
\hline $\begin{array}{l}\text { Article History } \\
\text { Received Apr 18, } 2020 \\
\text { Accepted Nov 26, } 2020 \\
\text { Published Dec 31, } 2020\end{array}$ & $\begin{array}{l}\text { Measuring the brightness of the night sky and determining the start of Fajr prayer } \\
\text { times can be done using SQM. Observations were made at OIF UMSU with } \\
\text { coordinates } 3^{\circ} 34^{\prime} 55.06^{\prime \prime} \mathrm{N} \text { and } 98^{\circ} 43^{\prime} 17.09^{\prime \prime} \text { E. The sky brightness was measured } \\
\text { using three SQMs mounted facing the zenith, eastern horizon, and western horizon. }\end{array}$ \\
\hline $\begin{array}{l}\text { Keywords: } \\
\text { Fajr prayer time } \\
\text { Light pollution } \\
\text { Night sky brightness } \\
\text { Sky Quality Meter }\end{array}$ & $\begin{array}{l}\text { western horizon are } 18.23 \text { mpsas, } 15.82 \mathrm{mpsas} \text {, and } 15.47 \mathrm{mpsas} \text {. The beginning of } \\
\text { fajr prayer time produced by SQM is after the beginning of fajr prayer time obtained } \\
\text { using the Accurate Times concerning the Sun's altitude } 18^{\circ} \text { below the horizon. The } \\
\text { difference obtained by SQM directed to the zenith, eastern horizon, and western } \\
\text { horizon is } 29.5 \text { minutes, } 36.7 \text { minutes, and } 39.5 \text { minutes. In other words, the } \\
\text { beginning of Fajr prayer time used in Indonesia is earlier than it should be. }\end{array}$ \\
\hline
\end{tabular}

To cite this article:

A. Y. Raisal, M. Hidayat, L. Hermawan, and A. J. Rakhmadi, "The Effect of the Installation Angle of the Sky Quality Meter on the Night Sky Brightness and the Beginning of the Fajr Prayer Time," Indones. Rev. Phys., vol. 3, no. 2, pp. $35-39,2020$.

\section{Introduction}

Observing the stars during the night is an exciting task to be done. That can only happen if the sky is free of light pollution. Globally, light emission has become a concern because it progressively decreases the possibility of seeing stars and reduces the number of light-sensitive species [1], [2]. However, the public often ignores these problems even though the adverse effects of light pollution are known. In contrast to other pollution, light pollution does not mean light that gets the impact of pollution, but light itself is a pollutant for the night sky's dark conditions [3].

The larger the human population, the more light is needed to illuminate human activities at night. Light pollution is a condition where, due to accidental illumination caused by improper lighting design, species are exposed to light at the wrong location, time, and intensity [4]. Light pollution has a significant effect on the night sky brightness. Therefore, it is necessary to measure the night sky brightness to determine the pollution level and become a reference for making policies in outdoor lighting systems [5]. The night sky brightness can be measured using the Sky Quality Meter (SQM). SQM is a system used for calculating night sky illumination. With a size that is easy to hold, this tool makes it possible for the general public to measure the night sky's quality whenever and wherever [6]. Besides, this tool is also the choice of night sky brightness researchers because it is user friendly and has good aftersales service and support [7]. SQM is also used to assess the eclipse period and the beginning of the Fajr prayer time [8], [9].

SQM has a field of view around $20^{\circ}$ with an uncertainty of the order of $10 \%$ [10]. With an area of view of $20^{\circ}$, SQM does not record the sky as a whole. In general, the Sun rises from the eastern horizon. The eastern horizon is bright earlier than the zenith and the western horizon. This study entitled the analysis of the influence of the Sky Quality Meter's angle on the night sky's brightness and the beginning of the Fajr prayer time. This study aims to determine whether there are differences in the value of the night sky brightness in the sky toward the east horizon, zenith, and west horizon. Besides, this study also aims to look for the effect of different SQM angles on the beginning of Fajr prayer time.

\section{Theory}

SQM is divided into two types, namely SQM without a lens and SQM using a lens. SQM that uses a lens (L) has a smaller view than without a lens around $20^{\circ}$, as shown in Figure 1. With a smaller field of view, the data reading will be more consistent when the nearest light source appears [11]. SQM measures the night sky brightness in magnitude per square arcsec or mathematically written mag/arcsec ${ }^{2}$ (mpsas). 


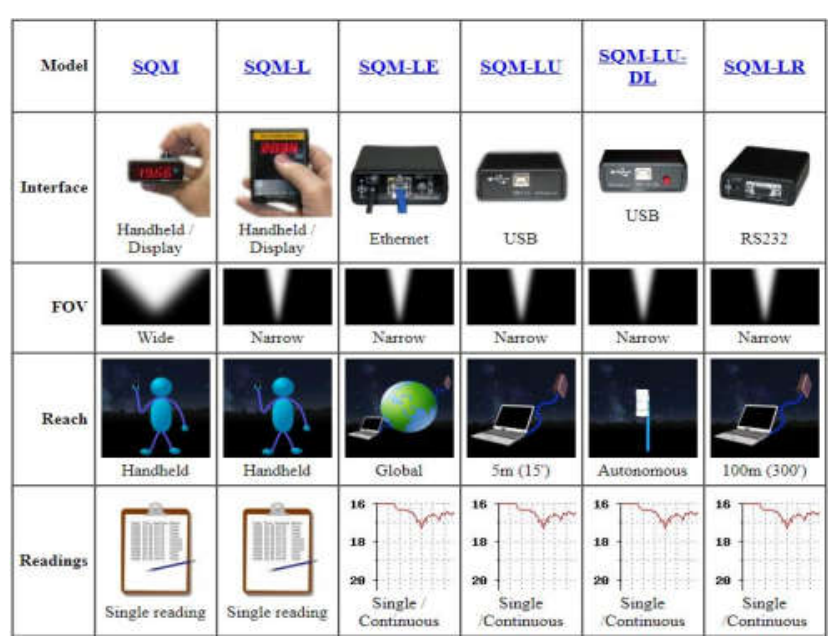

Figure 1. Different types of SQM (https://www.unihedron.com)

SQM is usually used to find out light pollution in an area. Light pollution is caused by the improper and excessive use of artificial light. Light pollution is a significant problem throughout the world, especially in urban areas. It causes an increase in the sky's light and prevents us from observing the dark starry sky [12]. Besides being used to measure the level of light pollution, SQM is also used to determine the beginning of the Fajr prayer time.

The beginning of Fajr prayer time is defined at the dawn of sadiq seen on the eastern horizon. The dawn sadiq is a white light visible on the east horizon and spread horizontally that appears before sunrise [9]. Dawn sadiq in astronomy is understood to be the astronomical dawn when the Sun is $18^{\circ}$ below the horizon, as seen in Figure 2. However, there are differences in the Sun's altitude in some countries, as shown in Table 1.

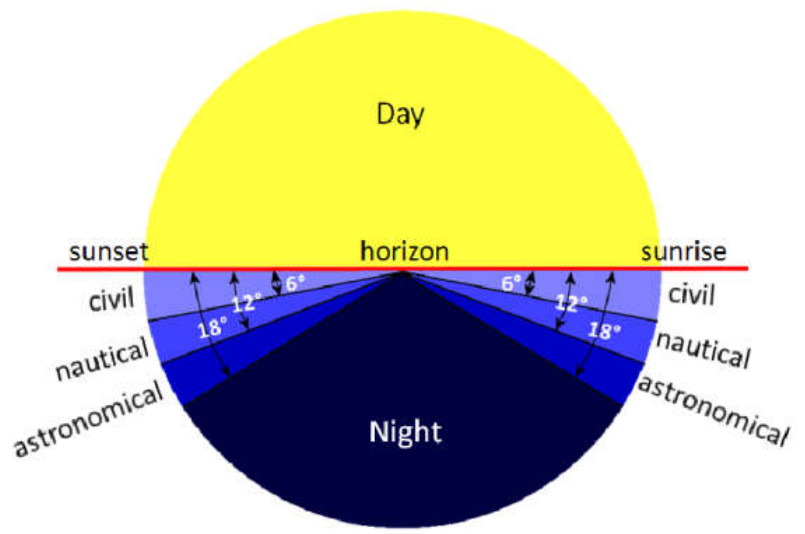

Figure 2. Overview of dusk and dawn (https://www.weather.gov)

When the SQM value decreases gradually, it is defined as the emergence of the dawn of Sadiq. To determine when the SQM value decreases gradually, one can use several methods, one of which is the moving average method [13].
Table 1. The Sun's altitude in determining the dawn Sadiq in several countries [14]

\begin{tabular}{clc}
\hline No & \multicolumn{1}{c}{ Convention } & $\begin{array}{c}\text { Sun's } \\
\text { altitude }\end{array}$ \\
\hline 1 & Shiah Ithna Ashari (Jaafari) & $-16^{\circ}$ \\
2 & Islamic Society of North America (ISNA) & $-15^{\circ}$ \\
3 & Muslim World League (MWL) & $-18^{\circ}$ \\
4 & Umm Al-qura Makkah & $-18.5^{\circ}$ \\
5 & Egyptian General Authority of Survey & $-19.5^{\circ}$ \\
6 & University of Islamic Science, Karachi & $-18^{\circ}$ \\
7 & Malaysia & $-20^{\circ}$ \\
\hline
\end{tabular}

\section{Method}

Observations were made at the Falak Observatory of the University of Muhammadiyah North Sumatra (OIF UMSU) with coordinates $3^{\circ} 34^{\prime} 55.06^{\prime \prime} \mathrm{N}$ and 98 $43^{\prime} 17.09^{\prime \prime}$ E. OIF UMSU is located on the 7 th floor of UMSU Postgraduate School, with a height of about 35 meters. The sky brightness was measured using three SQM mounted facing the east horizon, zenith, and west horizon. SQM, which measures the west horizon's direction, uses SQM-LU and SQM, which measures the zenith's direction and the east horizon uses SQM-LU-DL. SQM is set to collect the sky brightness value every 2 seconds. Measurements are taken throughout the night from sunset to sunrise. SQM data used is during the new moon phase. Hence, the moonlight does not affect the night sky brightness. The Moon Phase is one of the variables affecting the visibility of the night sky [15]. Besides, solar activity also affects the night sky brightness [16].

Determination of the beginning of Fajr prayer time using the moving average method. The moving average method is a method that is often used in technical analysis that shows the average value during a specified period. SQM retrieves data every 2 seconds then each difference value is sought by subtracting the second data from the first data. Furthermore, the difference in data is processed with a moving average. The interval used is 30 data. It was taken because of the need for prayer time with a resolution of 1 minute. Then the Fajr prayer time obtained by SQM is compared to the prayer time obtained by Accurate Times. This application can indicate the start of dawn based on the desired Sun's altitude. In this study, the Sun's altitude was chosen to be 180 below the horizon as a comparison.

\section{Results and Discussion}

Three SQMs are placed respectively towards the zenith, the western horizon, and the eastern horizon, as seen in Figure 3. Each SQM is inserted into the holding so that it can retrieve data even when it is raining. Data is collected from August 2018 to June 2019. During the new moon phase, the time taken is so that the moonlight does not affect the night sky brightness value. Furthermore, SQM directed to the zenith will be written as SQM1, SQM referred to the eastern horizon is written 
as SQM2, and SQM referred to the western horizon is written as SQM3.

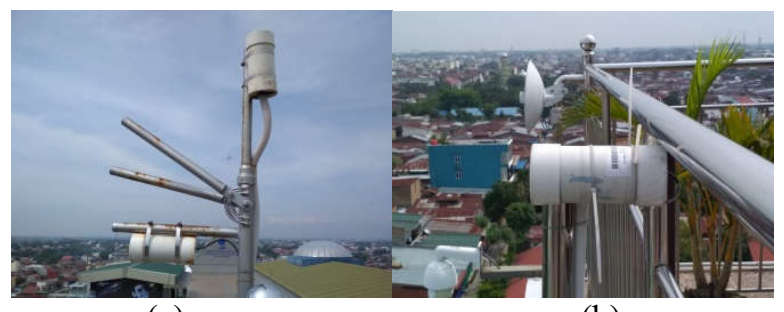

(a)

(b)

Figure 3. (a) SQM directed to zenith and east horizon. (b) SQM directed to west horizon.

SQM output data consists of universal time, local time, time, voltage temperature, sky brightness value, and data units. Furthermore, local time and sky brightness values will be used. The SQM data used is limited from midnight until SQM shows zero value. It is done to reduce the influence of light used by the community around the observation site.

Figure 4 is a graph of the night sky brightness against local time on June 5, 2019. The night sky brightness values of SQM1, SQM2, and SQM3 are shown by red, blue, and green lines. The night sky brightness value is relatively constant at night; then, it will decrease when the Sun rises. Figure 4 shows that the sky brightness value of SQM1 has a higher value than SQM2 and SQM3.

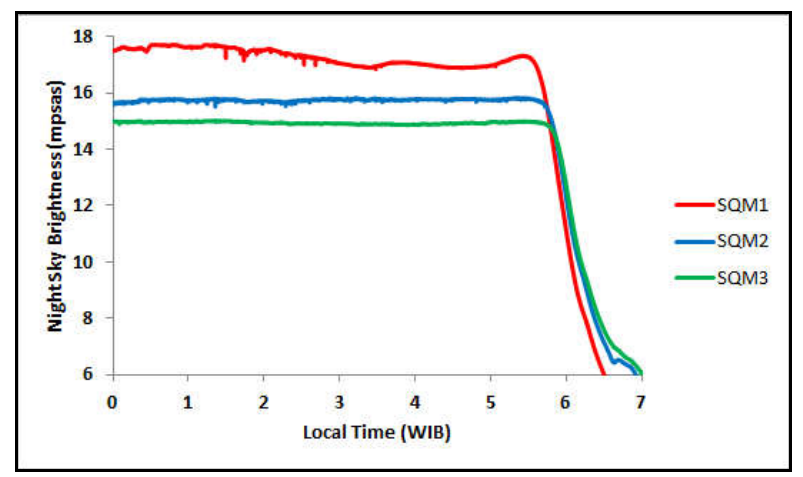

Figure 4. Night sky brightness against local time on June 5, 2019

During data collection, the effects of light, cloud, and air pollution are inevitable. It affects the value of the night sky brightness, which is read by SQM. Therefore the darkest value that can be obtained by SQM is taken during data collection. Table 2 shows the maximum night sky brightness values obtained by the three SQMs from August 2018 to June 2019. The maximum sky brightness value from SQM obtained varies. The maximum night sky brightness values obtained by SQM 1, SQM2, and SQM3 range from 17.43-18.89 mpsas, 15.57-16.01 mpsas, 15.02-15.71 mpsas. The average the night sky brightness value for SQM1, SQM2, and SQM3 are 18.23 \pm 0.49 mpsas, $15.82 \pm 0.15$ mpsas, and $15.47 \pm 0.23$ mpsas, respectively.
Table 2. The maximum night sky brightness values

\begin{tabular}{lccc}
\hline \multicolumn{1}{c}{ Date } & $\begin{array}{c}\text { SQM1 } \\
\text { (mpsas) }\end{array}$ & $\begin{array}{c}\text { SQM2 } \\
\text { (mpsas) }\end{array}$ & $\begin{array}{c}\text { SQM3 } \\
\text { (mpsas) }\end{array}$ \\
\hline $13 / 8 / 18$ & 18.71 & 15.76 & 15.68 \\
$11 / 9 / 18$ & 18.89 & 15.73 & 15.60 \\
$11 / 10 / 18$ & 17.59 & 15.57 & 15.39 \\
$9 / 11 / 18$ & 17.43 & 15.59 & 15.11 \\
$9 / 12 / 18$ & 18.00 & 15.81 & 15.68 \\
$8 / 1 / 19$ & 18.57 & 15.98 & 15.71 \\
$7 / 2 / 19$ & 18.37 & 15.90 & 15.61 \\
$8 / 3 / 19$ & 18.39 & 15.95 & 15.51 \\
$11 / 4 / 19$ & 18.22 & 15.93 & 15.42 \\
$6 / 5 / 19$ & 18.67 & 16.01 & 15.42 \\
$5 / 6 / 19$ & 17.71 & 15.82 & 15.02 \\
\hline \multicolumn{1}{c}{ Average } & 18.23 & 15.82 & 15.47 \\
\hline
\end{tabular}

The night sky brightness at the observation location based on the light pollution map info has a 19.02 mpsas, as shown in Figure 5. Compared with the maximum night sky brightness value obtained from SQM1, SQM2, and SQM3, there is a difference of 0.79 mpsas, 3.2 mpsas, and 3.55 mpsas.

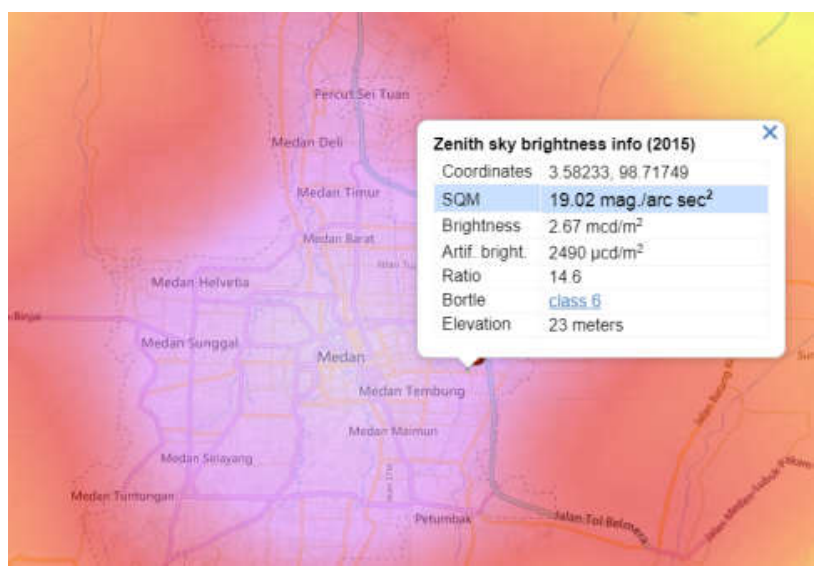

Figure 5. Night sky brightness values at the observation location (https://www.lightpollutionmap.info)

SQM LU and SQM LU-DL use lenses and have a field of view of $20^{\circ}$. Hence, the SQM directed to the west horizon and east horizon at a certain distance will immediately read the effect of the light produced by trespass light around the observation location. In the west of the observation site, several hotels are higher than the observation location. The value obtained by SQM directed to the western horizon has the lowest sky brightness value than the others.

Figure 6 shows a graph of the night sky brightness before sunrise on June 5, 2019. At the time before sunrise, the value of the brightness of the sky will decrease gradually. It is because the Sun's rays start to illuminate the Earth's atmosphere even though the Sun is still under the horizon. From Figure 6, it can be seen that SQM1 has gradually decreased faster than the other two. When the sky's brightness decreases gradually, this is considered the beginning of the fajr prayer. Nevertheless, it is complicated to determine when the sky's brightness value drops gradually by looking at Figure 6 . 


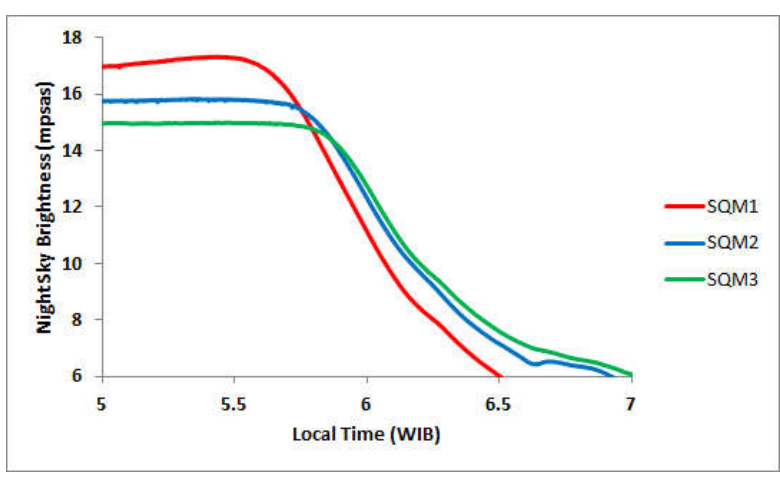

Figure 6. The brightness of the sky before sunrise on June 5, 2019.

Figure 7 shows a graph of the moving average value against SQM1 time on June 5, 2019. The sky brightness values obtained are not always the same. The moving average value indicates positive, zero, and negative values. This condition occurs due to light, cloud, and air pollution. The moving average value gradually decreases, or the negative value obtained is getting bigger at a specific time. It is due to the sky brightness value, which drops gradually. The time at which the moving average shows zero before the data afterward indicates a negative value is determined as the beginning of the Fajr prayer time.

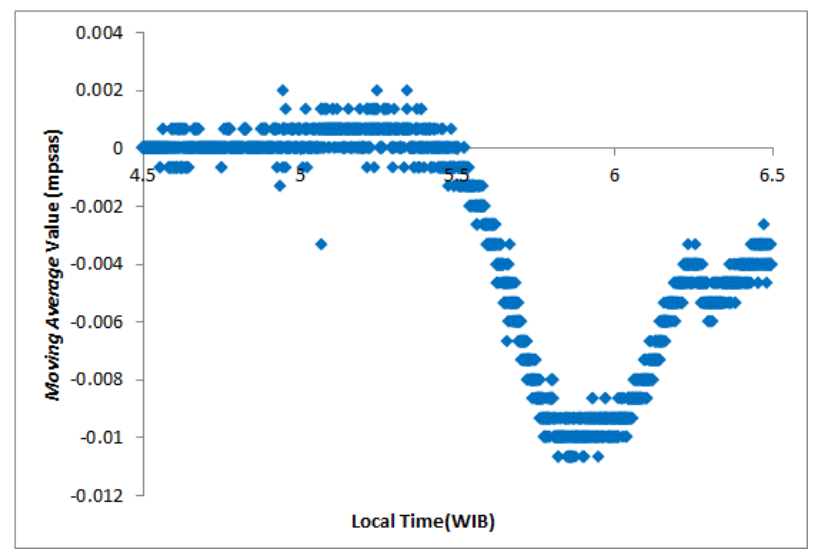

Figure 7. Graph of the moving average value against the local time in SQM1 on June 5, 2019

Table 3 shows the beginning of the Fajr prayer time based on SQM and Accurate Times. The beginning of Fajr prayer time at the Sun's altitude $18^{\circ}$ below the horizon is written as T18. It can be seen that the beginning of Fajr prayer time based on SQM is after the beginning of Fajr prayer time using Accurate Times.

Table 4 shows the differences between the beginning of Fajr prayer time of SQM and T18. The difference obtained varies from 19 minutes to 48 minutes. SQM1 has a smaller difference than SQM2 and SQM3. The average difference between the initial dawn time obtained by SQM1, SQM2, and SQM3 were $(29.5 \pm 8.9)$ minutes, $(36.7 \pm 6.3)$ minutes, and $(39.5 \pm 5.4)$ minutes, respectively. There are several high-rise buildings in the west of the observation site, while in the east, there are residential areas, so light pollution in the west and east is higher than the zenith direction. Besides, the sky on the eastern and western horizon is often covered with clouds. Therefore, the change in the sky brightness value is after the zenith.

Table 3. The beginning of Fajr prayer times based on SQM and Accurate Times

\begin{tabular}{lcccc}
\hline \multicolumn{1}{c}{ Date } & SQM1 & SQM2 & SQM3 & T18 \\
\hline $13 / 8 / 18$ & 05.30 & 05.38 & 05.42 & 05.11 \\
$11 / 9 / 18$ & 05.47 & 05.53 & 05.51 & 05.08 \\
$11 / 10 / 18$ & 05.46 & 05.49 & 05.48 & 05.01 \\
$9 / 11 / 18$ & 05.38 & 05.36 & 05.40 & 04.58 \\
$9 / 12 / 18$ & 05.32 & 05.43 & 05.42 & 05.05 \\
$8 / 1 / 19$ & 05.42 & 05.53 & 05.53 & 05.19 \\
$7 / 2 / 19$ & 05.48 & 05.57 & 06.03 & 05.28 \\
$8 / 3 / 19$ & 05.48 & 05.57 & 06.03 & 05.25 \\
$11 / 4 / 19$ & 05.35 & 05.45 & 05.47 & 05.11 \\
$6 / 5 / 19$ & 05.36 & 05.41 & 05.49 & 05.02 \\
$5 / 6 / 19$ & 05.30 & 05.39 & 05.43 & 04.59 \\
\hline
\end{tabular}

Table 4. The differences between the beginning of Fajr prayer time of SQM and T18.

\begin{tabular}{lccc}
\hline \multicolumn{1}{c}{ Date } & $\begin{array}{c}\text { SQM1 } \\
\text { (minutes) }\end{array}$ & $\begin{array}{c}\text { SQM2 } \\
\text { (minutes) }\end{array}$ & $\begin{array}{c}\text { SQM3 } \\
\text { (minutes) }\end{array}$ \\
\hline $13 / 8 / 18$ & 19 & 27 & 31 \\
$11 / 9 / 18$ & 39 & 45 & 43 \\
$11 / 10 / 18$ & 45 & 48 & 47 \\
$9 / 11 / 18$ & 40 & 38 & 42 \\
$9 / 12 / 18$ & 27 & 38 & 37 \\
$8 / 1 / 19$ & 23 & 34 & 34 \\
$7 / 2 / 19$ & 20 & 29 & 35 \\
$8 / 3 / 19$ & 23 & 32 & 38 \\
$11 / 4 / 19$ & 24 & 34 & 36 \\
$6 / 5 / 19$ & 34 & 39 & 47 \\
$5 / 6 / 19$ & 31 & 40 & 44 \\
\hline Average & 29.5 & 36.7 & 39.5 \\
\hline
\end{tabular}

From Table 4, it can be concluded that the beginning of Fajr prayer time obtained by SQM is longer than T18. When compared with the beginning of Fajr prayer time concerning the height of the Sun $20^{\circ}$ below the horizon, the difference obtained will be more significant than that shown in Table 4. At the same time, the beginning of Fajr prayer time, often used in Indonesia, uses a reference of $20^{\circ}$. It indicates that the Fajr prayer time used in Indonesia is earlier than it should be.

\section{Conclusion}

The night sky brightness values for SQM1, SQM2, and SQM3 are $(18.23 \pm 0.49)$ mpsas, $(15.47 \pm 0.23)$ mpsas, and $(15.82 \pm 0.15)$ mpsas, respectively. With a field of view of $20^{\circ}$, SQM directed to the west horizon, and the eastern horizon at a certain distance will immediately read the effect of light produced by trespass light around the observation site. So the night sky brightness value obtained by SQM2 and SMQ3 is smaller than SQM1. The night sky brightness value of SQM3 is the lowest compared to the others. Due to the west of the 
observation site, several hotels are higher than the observation location.

The beginning of dawn produced by SQM is after the beginning of dawn obtained using the Accurate Times with a height of $18^{\circ}$ below the horizon. The difference obtained by SQM directed to the zenith, eastern horizon, and western horizon is 29.5 minutes, 36.7 minutes, and 39.5 minutes. In other words, the beginning of Fajr prayer time used in Indonesia is earlier than it should be.

\section{References}

[1] R. Rajkhowa, "Light Pollution and Impact of Light Pollution," Int. J. Sci. Res., vol. 3, no. 10, pp. 861-867, 2014.

[2] S. Hideaki, "Research on Light Pollution by Using a Sky Quality Meter," Young Sci. J., vol. 6, no. 13, pp. 23-24, 2013.

[3] L. Nurfarida, P. M. Yusup, and N. Komariah, "Tingkat Pengetahuan Masyarakat Sekitar Observatorium Bosscha Lembang mengenai Polusi Cahaya," J. Kaji. Inf. dan Perpust., vol. 5, no. 1, pp. 13-22, Sep. 2017.

[4] A. Z. Kotarba, S. Chacewicz, and E. Żmudzka, "Night Sky Photometry Over Warsaw (Poland) Evaluated Simultaneously with Surface-Based and Satellite-Based Cloud Observations," J. Quant. Spectrosc. Radiat. Transf., vol. 235, pp. 95-107, Sep. 2019.

[5] S. Bará, "Anthropogenic Disruption of the Night Sky Darkness in Urban and Rural Areas," R. Soc. Open Sci., vol. 3, no. 10, pp. 1-14, Oct. 2016.

[6] P. Cinzano, "Night Sky Photometry with Sky Quality Meter," ISTIL Internal Report. pp. 1-14, 2005.

[7] N. F. Ngadiman, N. N. M. Shariff, and Z. S. Hamidi, "Sensor Technology for Night Sky Brightness Measurements in Malaysia," Int. J. Recent Technol. Eng., vol. 8, no. 6, pp. 198-202, Mar. 2020.
[8] Y. Pramudya and M. Arkanuddin, "The Sky Brightness Measurement during the 2016 Solar Eclipse in Ternate," J. Phys. Conf. Ser., vol. 771, no. 1, pp. 2-6, Nov. 2016.

[9] F. F. R. S. Hamdani and L. A. H. Noor, "The Dawn Sky Brightness Observations in the Preliminary Shubuh Prayer Time Determination," QIJIS (Qudus Int. J. Islam. Stud., vol. 6, no. 1, pp. 25-37, Jul. 2018.

[10] A. Bertolo, R. Binotto, S. Ortolani, and S. Sapienza, "Measurements of Night Sky Brightness in the Veneto Region of Italy: Sky Quality Meter Network Results and Differential Photometry by Digital Single Lens Reflex," $J$. Imaging, vol. 5, no. 56, pp. 1-13, May 2019.

[11] A. Hänel et al., "Measuring Night Sky Brightness: Methods and Challenges," J. Quant. Spectrosc. Radiat. Transf., vol. 205, pp. 278-290, Jan. 2018.

[12] J. Zamorano et al., "Testing Sky Brightness Models Against Radial Dependency: A Dense Two Dimensional Survey Around the City of Madrid, Spain," J. Quant. Spectrosc. Radiat. Transf., vol. 181, pp. 52-66, Sep. 2016.

[13] A. Y. Raisal, Y. Pramudya, O. Okimustava, and M. Muchlas, "Pemanfaatan Metode Moving Average dalam Menentukan Awal Waktu Salat Subuh Menggunakan Sky Quality Meter (SQM)," Al-Marshad J. Astron. Islam dan Ilmu-Ilmu Berkaitan, vol. 5, no. 1, pp. 1-13, 2019.

[14] S. A. M. Nor and M. Z. Zainuddin, "Sky Brightness for Determination of Fajr and Isha Prayer by Using Sky Quality Meter," Int. J. Sci. Eng. Res, vol. 3, no. 8, pp. 132-134, 2012.

[15] A. Y. Raisal, Y. Pramudya, O. Okimustava, and M. Muchlas, "The moon phases influence on the beginning of astronomical dawn determination in Yogyakarta," Int. J. Sci. Appl. Sci. Conf. Ser., vol. 2, no. 1, p. 1, 2017.

[16] I. Plauchu-Frayn et al., "Night sky brightness at San Pedro Martir observatory," Publ. Astron. Soc. Pacific, vol. 129, no. 973, pp. 1-13, 2017. 